\title{
Associations between model-predicted rivaroxaban exposure and patient characteristics and efficacy and safety outcomes in the prevention of venous thromboembolism
}

\author{
Isabel Reinecke ${ }^{1}$ - Alexander Solms ${ }^{2}$. Stefan Willmann ${ }^{3}$. Theodore E. Spiro ${ }^{4}$. Gary Peters ${ }^{5}$. Jeffrey I. Weitz ${ }^{6}$. \\ Wolfgang Mueck ${ }^{7}$. Dirk Garmann ${ }^{3}$. Stephan Schmidt ${ }^{8}$. Liping Zhang ${ }^{5} \cdot$ Keith A. A. Fox ${ }^{9} \cdot$ Scott D. Berkowitz ${ }^{4}(1)$
}

Published online: 23 April 2020

(c) The Author(s) 2020

\begin{abstract}
Anticoagulant plasma concentrations and patient characteristics might affect the benefit-risk balance of therapy. The study objective was to assess the impact of model-predicted rivaroxaban exposure and patient characteristics on outcomes in patients receiving rivaroxaban for venous thromboembolism (VTE) prophylaxis (VTE-P) after hip/knee replacement surgery. Post hoc exposure-response analyses were conducted using data from the phase 3 RECORD1-4 studies, in which 12,729 patients were randomized to rivaroxaban $10 \mathrm{mg}$ once daily or enoxaparin for $\leq 39$ days. Multivariate regression approaches were used to correlate model-predicted individual rivaroxaban exposures and patient characteristics with outcomes. In the absence of measured rivaroxaban exposure, exposure estimates were predicted based on individual increases in prothrombin time (PT) and by making use of the known correlation between rivaroxaban plasma concentration and dynamics of PT. No significant associations between rivaroxaban exposure and total VTE or major bleeding were identified. A significant association between exposure and a composite of major or non-major clinically relevant (NMCR) bleeding from day 4 after surgery was observed. The relationship was shallow, with an approximate predicted absolute increase in a composite of major or NMCR bleeding from 1.08 [95\% confidence interval (CI) 0.76-1.54] to 2.18\% (95\% CI 1.51-3.17) at the 5th and 95th percentiles of trough plasma concentration, respectively. In conclusion, based on the underlying data and analysis, no reliable target window for exposure with improved benefit-risk could be identified within the investigated exposure range. Hence, monitoring rivaroxaban levels is unlikely to be beneficial in VTE-P.
\end{abstract}

Keywords Drug monitoring $\cdot$ Exposure-response $\cdot$ Rivaroxaban $\cdot$ Venous thromboembolism

Isabel Reinecke is employed by Bayer AB in Solna, Sweden; this work was performed on behalf of Bayer AG, Research \& Development, Pharmaceuticals, Berlin, Germany.

Electronic supplementary material The online version of this article (https://doi.org/10.1007/s11239-020-02078-8) contains supplementary material, which is available to authorized users.

Scott D. Berkowitz

scott.berkowitz@bayer.com

Bayer AB, Solna, Sweden

2 Clinical Pharmacometrics, Bayer AG, Berlin, Germany

3 Clinical Pharmacometrics, Bayer AG, Wuppertal, Germany

4 Bayer U.S., LLC, Research \& Development, Pharmaceuticals, 100 Bayer Boulevard, Whippany, NJ 07981, USA

5 Janssen Research \& Development, LLC, Raritan, NJ, USA

\section{Highlights}

- Employing multivariate regression approaches, post hoc exposure-response analyses were performed using data from the RECORD1-4 studies to assess the

6 McMaster University, and the Thrombosis \& Atherosclerosis Research Institute, Hamilton, ON, Canada

7 Clinical Pharmacokinetics, Bayer AG, Wuppertal, Germany

8 Center for Pharmacometrics and Systems Pharmacology, Department of Pharmaceutics, College of Pharmacy, University of Florida, Orlando, FL, USA

9 Centre for Cardiovascular Science, The University of Edinburgh, Edinburgh, UK 
impact of predicted rivaroxaban exposure and patient characteristics on clinical outcomes.

- Rivaroxaban exposure-response relationships with both efficacy and safety were shallow sloped or absent within the investigated exposure range.

- Monitoring rivaroxaban levels is unlikely to be beneficial when used for thromboprophylaxis.

\section{Introduction}

Rivaroxaban, an oral direct factor Xa inhibitor, is approved for several indications, including venous thromboembolism prophylaxis (VTE-P) in adults undergoing elective total hip/knee replacement (THR/TKR) surgery [1].

Rivaroxaban was developed to provide predictable anticoagulation with fixed-dose administration, without the need to routinely measure drug levels or perform coagulation assays for dose adjustment. This approach is supported by the high bioavailability of rivaroxaban when administered with food, and the low potential for food and drug interactions [2-4], which minimize variability in rivaroxaban exposure [3, 4].

Data from phase 2 dose-ranging studies in patients receiving rivaroxaban for VTE-P after THR (ODIXa-Hip2, ODIXa-Hip-OD) or TKR (ODIXa-Knee) [5-8] supported the investigation of rivaroxaban $10 \mathrm{mg}$ once daily (OD) in the phase 3 RECORD program [9-14], leading to approval of this regimen for VTE-P [1]. Phase 2 data were also used to construct population pharmacokinetic (popPK) models to characterize the pharmacokinetics of rivaroxaban in patients undergoing THR/TKR $[15,16]$. The models reliably predicted the pharmacokinetic profile of rivaroxaban and demonstrated a strong correlation between prothrombin time (PT) prolongation (obtained using a sensitive thromboplastin reagent) and rivaroxaban plasma concentration $[2,15,16]$.

Patient characteristics affect the benefits and risks (e.g., bleeding) associated with anticoagulation therapy $[1,17]$; for example, advanced age and impaired renal function are associated with increased rivaroxaban exposure [1]. In patients receiving anticoagulants for VTE-P, factors such as previous history of venous thromboembolism (VTE), active cancer and its treatments, and surgery type, if applicable, affect the risk of VTE and/or bleeding [18-21].

Given that rivaroxaban exposure may vary between patients, it has been proposed that therapeutic drug monitoring (i.e., plasma-concentration-based dose adjustment) may enhance the individual benefit-risk ratio of treatment [22]. Such treatment individualization requires a robust understanding and quantification of the association between exposure and safety and efficacy. Owing to a lack of observed pharmacokinetic data in the phase 3 RECORD trials, individual rivaroxaban exposure was predicted using a previously developed popPK model, individual covariates and PT measurements [23, 24]. Using data from the RECORD1-4 studies and individually predicted derived rivaroxaban exposure parameters, post hoc model-predicted exposure-response analyses were performed to assess the impact of rivaroxaban exposure and patient characteristics on clinical outcomes in patients receiving rivaroxaban for VTE-P after elective THR surgery ( 35 days of treatment) or TKR surgery (12 days of treatment). The data reported here accompany the results of a similar analysis in which the impact of rivaroxaban exposure and patient characteristics on clinical outcomes were assessed in patients receiving rivaroxaban for VTE treatment.

\section{Methods}

\section{Study design}

Full details of the methodology and ethical conduct of RECORD1-4 (Table 1) have been published previously $[9,10,13,14]$. Briefly, in RECORD1-4, 12,729 patients who were undergoing elective THR or TKR were randomized to receive oral rivaroxaban (10 $\mathrm{mg}$ once daily [OD]) or subcutaneous enoxaparin for $\leq 39$ days (THR) or $\leq 14$ days (TKR). The efficacy outcome evaluated in the current exposure-response analysis was total VTE (i.e., any objectively documented symptomatic or asymptomatic deep vein thrombosis [DVT; proximal and/or distal], nonfatal pulmonary embolism [PE] or death). Safety outcomes included major bleeding and the composite outcome of major or non-major clinically relevant (NMCR) bleeding (Table 1). The exposure-efficacy analysis included asymptomatic events detected by bilateral venography and objectively confirmed symptomatic events from the first day of rivaroxaban administration until day 42 (RECORD1\&2) or day 17 (RECORD3\&4). The exposure-safety analysis included events occurring from the first day of rivaroxaban administration until 2 days after the last dose. Bleeding events were separated into events occurring up to 3 days after surgery (on days 1-4) and more than 3 days after surgery (after day 4), to account for the influence of the surgical procedure on bleeding.

\section{Patient characteristics}

Patient characteristics considered in the exposure-response evaluation (including potential risk factors for clinical outcomes) were identified a priori based on a literature review [20, 25-29] and experience in RECORD1-4 [9, 10, 13, 14]. 
Table 1 Description of the studies and outcomes included in the exposure-response analyses

\begin{tabular}{|c|c|c|c|c|}
\hline Study & RECORD1 [9] & RECORD2 [10] & RECORD3 [13] & RECORD4 [14] \\
\hline Population & \multicolumn{2}{|c|}{ Patients undergoing elective THR } & \multicolumn{2}{|c|}{ Patients undergoing elective TKR } \\
\hline $\begin{array}{l}\text { Total number of patients } \\
\text { randomized }\end{array}$ & \multicolumn{4}{|l|}{12,729} \\
\hline Pertinent exclusion criteria & \multicolumn{2}{|c|}{ Concomitant use of HIV protease inhibitors } & \multicolumn{2}{|c|}{$\begin{array}{l}\text { Concomitant use of strong CYP3A4 inhibitors, } \\
\text { such as ketoconazole or protease inhibitors }\end{array}$} \\
\hline $\begin{array}{l}\text { Rivaroxaban dose and regi- } \\
\text { men }\end{array}$ & \multicolumn{2}{|l|}{$\begin{array}{l}10 \mathrm{mg} \text { OD } \\
35 \pm 4 \text { days }\end{array}$} & \multicolumn{2}{|l|}{$\begin{array}{l}10 \mathrm{mg} \text { OD } \\
12 \pm 2 \text { days }\end{array}$} \\
\hline $\begin{array}{l}\text { Comparator dose and regi- } \\
\text { men }\end{array}$ & $\begin{array}{l}\text { Enoxaparin } 40 \mathrm{mg} \text { OD } \\
35 \pm 4 \text { days }\end{array}$ & $\begin{array}{l}\text { Enoxaparin } 40 \mathrm{mg} \text { OD } \\
12 \pm 2 \text { days followed by } \\
\text { placebo }\end{array}$ & $\begin{array}{l}\text { Enoxaparin } 40 \mathrm{mg} \text { OD } \\
12 \pm 2 \text { days }\end{array}$ & $\begin{array}{l}\text { Enoxaparin } 30 \mathrm{mg} \mathrm{BID} \\
12 \pm 2 \text { days }\end{array}$ \\
\hline Maximum follow-up & \multicolumn{4}{|l|}{65 days } \\
\hline Mean treatment duration & \multicolumn{2}{|l|}{$\begin{array}{l}\text { Rivaroxaban: } 33.5 \text { days } \\
\text { Enoxaparin: } 33.7 \text { days }\end{array}$} & \multicolumn{2}{|l|}{$\begin{array}{l}\text { Rivaroxaban: } 11.7 \text { days } \\
\text { Enoxaparin: } 11.0 \text { days }\end{array}$} \\
\hline $\begin{array}{l}\text { Total number of patients for } \\
\text { ER analysis }\end{array}$ & \multicolumn{4}{|l|}{$\begin{array}{l}6097 \text { (safety) } \\
4246 \text { (efficacy) }\end{array}$} \\
\hline $\begin{array}{l}\text { Efficacy outcomes for ER } \\
\text { analysis }\end{array}$ & \multicolumn{4}{|c|}{$\begin{array}{l}\text { Total VTE: composite of objectively documented asymptomatic or symptomatic DVT (proximal and/or distal), } \\
\text { non-fatal PE and death from any cause }\end{array}$} \\
\hline $\begin{array}{l}\text { Safety outcomes for ER } \\
\text { analysis }\end{array}$ & \multicolumn{4}{|c|}{$\begin{array}{l}\left.\text { 1. RECORD major bleeding }{ }^{\mathrm{a}} \text { (days } 1-4 \text { and after day } 4\right) \\
\left.\text { 2. Major or NMCR }{ }^{\mathrm{b}} \text { bleeding (days } 1-4 \text { and after day } 4\right)\end{array}$} \\
\hline
\end{tabular}

$B I D$ twice daily, CYP3A4 cytochrome P450 3A4, DVT deep vein thrombosis, ER exposure-response, $H I V$ human immunodeficiency virus, $N M C R$ non-major clinically relevant, $O D$ once daily, $P E$ pulmonary embolism, THR total hip replacement, TKR total knee replacement, VTE venous thromboembolism

${ }^{a}$ RECORD major bleeding was defined as: fatal bleeding; bleeding into a critical organ; bleeding that required re-operation; or clinically overt extra-surgical-site bleeding associated with a decrease in hemoglobin of $\geq 2 \mathrm{~g} / \mathrm{dL}$ or requiring a transfusion of $\geq 2$ units of whole blood or packed cells

${ }^{\mathrm{b}} \mathrm{NMCR}$ bleeding was defined as: overt bleeding that did not meet the criteria for major bleeding but was associated with medical intervention; unscheduled contact with a physician; interruption or discontinuation of a study drug; or discomfort or impairment of activities of daily life

Continuous variables, including age, were categorized to aid interpretation.

\section{Model-predicted rivaroxaban exposure}

Because rivaroxaban plasma concentrations were not measured in the phase 3 RECORD studies, a previously reported integrated popPK model was employed to predict individual rivaroxaban exposure estimates using patient characteristics known to influence rivaroxaban pharmacokinetics [24]. Trough plasma concentration $\left(\mathrm{C}_{\text {trough }}\right)$, maximum plasma concentration $\left(\mathrm{C}_{\max }\right)$ and area under the plasma concentration-time curve from 0 to $24 \mathrm{~h}\left(\mathrm{AUC}_{0-24}\right)$ at steady state were predicted for each patient based on individual characteristics (age, weight, renal function measured as calculated creatinine clearance $[\mathrm{CrCl}]$ using the Cockcroft-Gault equation, and sex) and rivaroxaban dose. Using patient characteristics alone to predict individual rivaroxaban exposure might not adequately reflect the expected variability; therefore, a new approach to enhance model-predicted rivaroxaban exposures based on the collateral correlation between rivaroxaban plasma concentration and measured PT was applied to 5293 patients receiving rivaroxaban for VTE-P, as described previously [23].
Exposure-efficacy and exposure-safety analyses were performed in patients who received at least one blinded dose of study drug, had undergone the appropriate surgery and had an adequate assessment of thromboembolism, and for those who underwent randomization and received at least one dose of study drug, respectively.

\section{Regression analyses}

Exposure-response relationships were evaluated using logistic regression with application of penalized likelihood (Firth method) to avoid small-sample bias [30]. Time-to-event analysis was not expected to provide additional information in these contexts owing to the short ( $\leq 39$ days) treatment duration. The analysis was conducted using $\mathrm{R}$ (version 3.3.0) and the logistf and survival packages.

Relationships between rivaroxaban exposure metrics, patient characteristics and each of the efficacy and safety outcomes were quantified using the following methods. Initially, univariate regression analyses were performed using $\mathrm{C}_{\text {trough }}, \mathrm{C}_{\text {max }}$ or $\mathrm{AUC}_{0-24}$ as independent variables, assuming a linear relationship for the continuous exposure measures (logistic regression). The exposure metric most strongly associated with the occurrence of an event, indicated by 
the lowest Akaike information criterion (AIC) value generated by the univariate analyses, was then combined with the selected patient characteristics for the VTE-P indication as independent variables for predicting the probability of the outcomes in multivariate regression analyses (the full model). Age and $\mathrm{CrCl}$ were expected to influence outcomes [1], and were, therefore, forced into the models regardless of their statistical significance. This forced inclusion was done to avoid bias in the variable selection process due to confounding variables, because a patient's $\mathrm{CrCl}$ and age, for example, correlate with rivaroxaban exposure. An additional covariate forced into the model was type of surgery (THR or TKR) for the efficacy analyses. With selected variables forced into the model, backward elimination, based on AIC values, was performed on the other variables until no further variable was removed. All statistically non-significant variables, with the exception of the forced input variables, were removed to generate the final model. Statistical significance refers to covariates, including exposure, showing a $\mathrm{p}$ value no greater than 0.01 according to the likelihood ratio test.

If exposure was included in the final model, odds ratios (ORs) were generated for the variables in the final models and shown in forest plots. The reference category was the most-commonly observed category for the variable, except for region, for which Western Europe was set as the reference. For exposure metrics, the median value of each dose was set as the reference to represent the typical exposure in a patient at that dose level. The final models were used to simulate the probability of efficacy or safety events versus exposure in a typical patient population (i.e., with individual patient characteristics set to reference values).

\section{Results}

\section{Patient characteristics}

Supplemental Table 1 shows the patient characteristics selected for evaluation. Supplemental Table 2 shows the count and proportion of patients in the RECORD1-4 studies (safety population, $n=6097$; efficacy population, $n=4246$ ) with each characteristic. Among the 6097 patients included in the safety analysis, almost half $(47 \%)$ were $<65$ years of age, $38 \%$ were $65-75$ years of age, $15 \%$ were $>75$ years of age, $61 \%$ were female and $55 \%$ underwent THR. Overall, $7 \%$ had $\mathrm{CrCl}<50 \mathrm{~mL} / \mathrm{min}$ and $1 \%$ had active malignancy at randomization.

\section{Rivaroxaban exposure predictions and event rates}

Rivaroxaban exposure predictions are shown in Supplemental Table 3. The derived, model-based exposure metrics showed moderate variability, with $\mathrm{C}_{\text {trough }}$ being the most variable parameter (coefficient of variation: 61.3-66.6\%). The predicted exposure metrics were all highly correlated (correlation coefficient $\geq 0.60$ ) within a given individual. The observed efficacy and safety outcome event rates are presented in Supplemental Table 4.

\section{Regression analyses}

Results of the final exposure-response models are summarized in Table 2.

\section{Exposure-efficacy analysis}

In the univariate regression analysis, $\mathrm{C}_{\max }$ was associated with the lowest AIC value when fitting the exposure metrics $\mathrm{C}_{\text {trough }}, \mathrm{C}_{\max }$ or $\mathrm{AUC}_{0-24}$, and was therefore selected for further investigation (Supplemental Table 5). Given that
Table 2 Results of the final exposure-response models

\begin{tabular}{llll}
\hline Variables & Efficacy & Safety & \\
\cline { 4 - 4 } & Total VTE & Major bleeding & Major or NMCR bleeding \\
\hline $\mathrm{TKR}^{\mathrm{a}}$ & $\mathrm{X}$ & $\mathrm{NA}$ & NA \\
$\mathrm{Age}^{\mathrm{a}}$ & $\mathrm{n} . \mathrm{s}$ & $\mathrm{n} . \mathrm{s}$ & $\mathrm{n} . \mathrm{s}$ \\
$\mathrm{CrCl}^{\mathrm{a}}$ & $\mathrm{n} . \mathrm{s}$ & $\mathrm{n} . \mathrm{s}$ & $\mathrm{n} . \mathrm{s}$ \\
Best exposure & n.s & n.s & $\mathrm{C}_{\text {trough }}$ (after day 4 only) \\
$\begin{array}{l}\text { Other significant } \\
\text { covariate }\end{array}$ & None & None & Hospital region, sex (days 1-4 only) \\
\hline
\end{tabular}

$\mathrm{X}$ denotes statistically significant exposure-response relationship $(\mathrm{p} \leq 0.01)$

$\mathrm{CrCl}$ creatinine clearance, $C_{\text {trough }}$ trough plasma concentration, $N A$ not applicable, NMCR non-major clinically relevant, n.s. not significant, TKR total knee replacement, VTE venous thromboembolism

${ }^{\mathrm{a}}$ Forced input variables 
model-predicted $\mathrm{C}_{\max }$ was removed during the backward elimination process, no significant association between rivaroxaban exposure and the composite efficacy outcome of total VTE was present in the RECORD1-4 studies (Supplemental Table 6). Age and $\mathrm{CrCl}$ were not significantly associated with total VTE in the final model; however, patients undergoing TKR were more likely to experience total VTE than those undergoing THR (OR: 5.91 [95\% confidence interval (CI) 4.09-8.76]) (Supplemental Table 7). No significant associations between other patient characteristics and total VTE were identified.

\section{Exposure-safety analysis}

$\mathrm{C}_{\max }$ was selected for further investigation in the exposure-safety analyses for bleeding events occurring $\leq 3$ days after THR/TKR (on days 1-4), because it was the exposure metric associated with the lowest $\mathrm{AIC}$ value in the univariate regression analyses. For similar reasons, $\mathrm{AUC}_{0-24}$ and $\mathrm{C}_{\text {trough }}$ were selected for inclusion in the full models for major bleeding events occurring after day 4 and for a composite of major or NMCR bleeding events occurring after day 4, respectively (Supplemental Table 5).

For major bleeding during days 1-4 and after day 4, the overall number of events was low (11 of 6097 patients [0.18\%] during days $1-4$, and 11 of 5995 patients after day 4 [0.18\%]; Supplemental Table 4) and no significant exposure-response relationship could be established
(Supplemental Table 8). In addition, there was no significant association between any of the evaluated patient characteristics, including the forced input variables of age and $\mathrm{CrCl}$, and major bleeding (Supplemental Table 9).

For the composite of major or NMCR bleeding during days 1-4, no significant exposure-response relationship could be established (Supplemental Table 8). Of the patient characteristics evaluated, only male versus female sex (OR 3.05 [95\% CI 1.92-4.93]; p < 0.00001) and hospital region (OR 1.63 [95\% CI 0.98-2.70] for the USA/Canada vs Western Europe; $p=0.001$ ) were significantly associated with this outcome (Supplemental Table 9). For major or NMCR bleeding after day 4, a statistically significant exposure-response relationship was observed, with ORs of 0.82 (95\% CI: 0.77-0.87) and 1.68 (95\% CI: 1.21-2.33) for $\mathrm{C}_{\text {trough }}$ at the 5th and 95th percentiles of exposure versus the median, respectively (Fig. 1a). No patient characteristics, including the forced input variables of age and $\mathrm{CrCl}$, were significantly associated with the composite of major or NMCR bleeding after day 4 (Supplemental Table 9; Fig. 1a).

\section{Expected probability of safety events during treatment with rivaroxaban}

The relationship between model-predicted exposure $\left(\mathrm{C}_{\text {trough }}\right)$ and the probability of major or NMCR bleeding with rivaroxaban treatment after day 4 was shallow, with an approximate predicted absolute increase in a composite of major or a

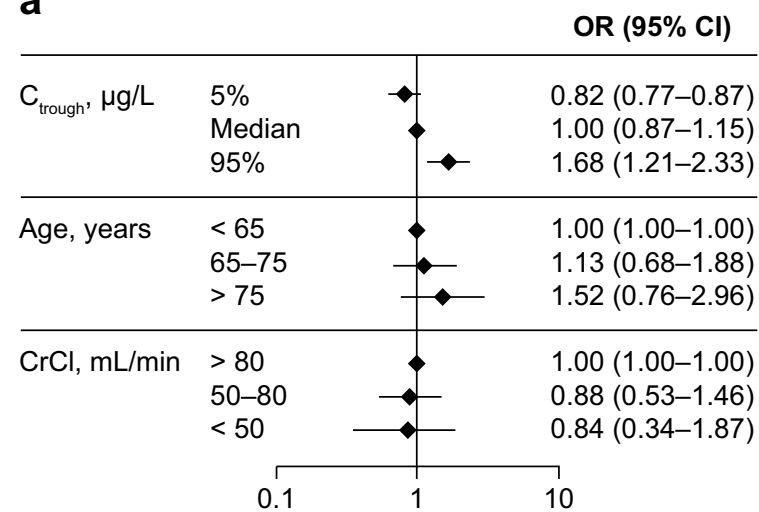

OR for major or NMCR bleeding $(95 \% \mathrm{Cl})$

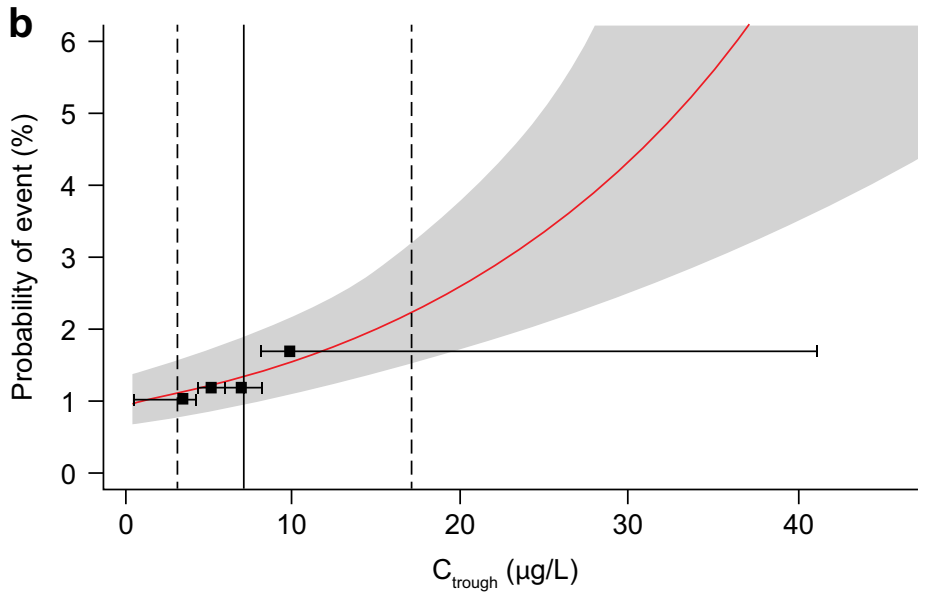

lines indicate the 5th and 95th percentiles of exposure in the population, and the vertical solid line indicates the median. Horizontal solid black lines represent quartiles of exposure in the reference population (age $<65$ years and $\mathrm{CrCl}>80 \mathrm{~mL} / \mathrm{min}$ ), and black squares represent the observed fraction of events at the median of exposure within each quartile of exposure. $\mathrm{CI}$ confidence interval, $\mathrm{CrCl}$ creatinine clearance, $C_{\text {trough }}$ trough plasma concentration, $N M C R$ non-major clinically relevant, $O R$ odds ratio, VTE- $P$ venous thromboembolism prophylaxis 
NMCR bleeding from 1.08 (95\% CI $0.76-1.54)$ to $2.18 \%$ (95\% CI 1.51-3.17) at the 5th and 95th percentiles of $\mathrm{C}_{\text {trough }}$, respectively (Fig. 1b). Although a significant relationship was identified, the shape of this relationship could not be reliably evaluated, most likely due to the overall low event rates. In particular, at the upper end of the investigated exposure range the uncertainty in the model-predicted event rate was relatively high as indicated by the wide confidence interval (Fig. 1b).

\section{Discussion}

In this analysis, no exposure-response relationships were observed for total VTE and major bleeding events in patients receiving rivaroxaban $10 \mathrm{mg}$ OD for VTE-P. However, significant reductions in the risk of VTE were observed with rivaroxaban versus enoxaparin in the RECORD1-4 studies $[9,10,13,14]$. Taken together, these findings support the rivaroxaban $10 \mathrm{mg}$ OD fixed-dose regimen.

Exposure, particularly $\mathrm{C}_{\text {trough }}$, was the predominant risk factor for a composite of major or NMCR bleeding after THR/TKR from day 4, with a shallow-sloped exposure-response relationship. These findings are consistent with data from VTE-P phase 2 trials, in which no significant dose-response relationship was observed for total VTE, but postoperative bleeding events increased dose-dependently over the range 5-40 $\mathrm{mg}$ OD and 2.5-30 $\mathrm{mg}$ twice daily [6, $7,31]$.

In this analysis, only male versus female sex and hospital region were significantly associated with major or NMCR bleeding during days 1-4 after THR/TKR. Patient characteristics, including age and $\mathrm{CrCl}$, were not significantly associated with major or NMCR bleeding after day 4 or with major bleeding alone.

Consistent with our findings, a previous study in patients receiving apixaban after THR/TKR reported no statistically significant exposure-efficacy relationship [32]. Predicted bleeding frequencies for patients with risk factors for high apixaban exposure were similar to those for the reference population, supporting the recommendation that apixaban dose adjustment is not necessary to reduce bleeding risk in these patients [32]. Furthermore, since their introduction for VTE-P, other anticoagulants (unfractionated heparin, low molecular weight heparins, indirect and direct factor Xa inhibitors, and direct thrombin inhibitors) have been used in fixed doses, without adjustment.

Limitations of this analysis include the paucity of direct pharmacokinetic measurements and consequent use of model-predicted exposure data, which could not fully reproduce the inter-patient variability expected in a real-world patient population. The exposure-response analyses were post hoc, and the phase 3 studies included, which were of relatively short duration, were not designed to evaluate exposure-response relationships and the impact of patient characteristics on outcomes. Finally, these analyses were based on only the approved $10 \mathrm{mg}$ OD dosing regimen for VTE-P; exposure-response relationships with other regimens cannot be excluded. To more reliably draw conclusions on the utility of a therapeutic drug monitoring treatment approach, and to establish a treatment algorithm that is trusted to improve individual patient treatment outcome, further systematic evaluation of data and methods and correlation with clinical events in outcomes trials would be needed.

\section{Conclusions}

In this analysis, model-predicted rivaroxaban exposure-response relationships were shallow or absent for both safety and efficacy outcomes. Based on the underlying studies, no reliable target window for exposure with improved benefit-risk could be identified within the investigated exposure range and there was no evidence that the benefit-risk balance of rivaroxaban would be enhanced by implementing therapeutic drug monitoring as a routine measure [33]. These results support the approved, fixed-dose rivaroxaban regimen for VTE-P. However, as observed with other direct oral anticoagulants, evaluating patient characteristics, particularly renal function, also provides valuable information when considering treatment with rivaroxaban.

Acknowledgements This work was conducted at Bayer AG, Bayer U.S., LLC, and Janssen Research \& Development, LLC. Emma Bolton of Oxford PharmaGenesis, Oxford, UK, provided medical writing support, which was funded by Bayer AG, Berlin, Germany. The authors would like to thank Xiaoyu Yan, Dagmar Kubitza and Martin Homering for their contributions related to the work described in this manuscript.

Author contributions All authors contributed to study concept and design, analysis and/or interpretation of data, critical writing and revising the manuscript. All authors approved the final version of the manuscript to be published.

\section{Compliance with ethical standards}

Conflict of interest This analysis, including its design, and the collection, analysis and interpretation of data, were funded by Bayer AG, Berlin, Germany, and Janssen Research \& Development, LLC, Raritan, NJ, USA. The writing of the report and decision to submit the work for publication were carried out jointly by the authors, some of whom are employees of Bayer AG and Janssen Research \& Development, LLC. All authors had access to the study data. Dirk Garmann, Wolfgang Mueck, Alexander Solms and Stefan Willmann are employees of Bayer AG; Isabel Reinecke is an employee of Bayer AB; Scott D. Berkowitz and Theodore E. Spiro are employees of Bayer U.S., LLC. This work was conducted within the scope of their employment, and no additional payment was received. Gary Peters and Liping Zhang are employees of Janssen Research \& Development, LLC, and own stock in Johnson \& Johnson. This work was conducted within the scope of 
their employment, and no additional payment was received. Keith A. A. Fox has received grants and honoraria relating to this work from Bayer AG and Janssen Research \& Development, LLC, and he has received grants for unrelated work from AstraZeneca and honoraria from Sanofi/Regeneron and Verseon. Stephan Schmidt is a paid consultant for Bayer AG. Jeffrey I. Weitz is a consultant for and has received honoraria from Bayer, Boehringer Ingelheim, Bristol-Myers Squibb, Daiichi Sankyo, Ionis, Janssen, Merck, Novartis, Pfizer and Portola.

Ethical approval All procedures performed in studies involving human participants were in accordance with the ethical standards of the institutional and/or national research committee; details have been published previously $[9,10,13,14]$.

Informed consent Informed consent was obtained from all individual participants included in the studies; details have been published previously $[9,10,13,14]$.

Research involving human and animal participants This article does not contain any studies with animals performed by any of the authors.

Open Access This article is licensed under a Creative Commons Attribution 4.0 International License, which permits use, sharing, adaptation, distribution and reproduction in any medium or format, as long as you give appropriate credit to the original author(s) and the source, provide a link to the Creative Commons licence, and indicate if changes were made. The images or other third party material in this article are included in the article's Creative Commons licence, unless indicated otherwise in a credit line to the material. If material is not included in the article's Creative Commons licence and your intended use is not permitted by statutory regulation or exceeds the permitted use, you will need to obtain permission directly from the copyright holder. To view a copy of this licence, visit http://creativecommons.org/licenses/by/4.0/.

\section{References}

1. Bayer Pharma AG (2017) Rivaroxaban Summary of Product Characteristics. https://www.ema.europa.eu/docs/en_GB/document library/EPAR_-_Product_Information/human/000944/WC500 057108.pdf. Accessed Oct 2019.

2. Mueck W, Schwers S, Stampfuss J (2013) Rivaroxaban and other novel oral anticoagulants: pharmacokinetics in healthy subjects, specific patient populations and relevance of coagulation monitoring. Thromb J 11(1):10. https://doi.org/10.1186/1477-9560-11-10

3. Mueck W, Stampfuss J, Kubitza D, Becka M (2014) Clinical pharmacokinetic and pharmacodynamic profile of rivaroxaban. Clin Pharmacokinet 53(1):1-16. https://doi.org/10.1007/s4026 2-013-0100-7

4. Sato M, Narukawa M (2015) Factors affecting intrasubject variability of PK exposure: absolute oral bioavailability and acidic nature of drugs. Int J Clin Pharmacol Ther 53(11):955-962. https ://doi.org/10.5414/CP202399

5. Eriksson BI, Borris L, Dahl OE, Haas S, Huisman MV, Kakkar AK, Misselwitz F, Kalebo P (2006) Oral, direct Factor Xa inhibition with BAY 59-7939 for the prevention of venous thromboembolism after total hip replacement. J Thromb Haemost 4(1):121128. https://doi.org/10.1111/j.1538-7836.2005.01657.x

6. Eriksson BI, Borris LC, Dahl OE, Haas S, Huisman MV, Kakkar AK, Misselwitz F, Muehlhofer E, Kalebo P (2007) Dose-escalation study of rivaroxaban (BAY 59-7939)-an oral, direct Factor Xa inhibitor-for the prevention of venous thromboembolism in patients undergoing total hip replacement. Thromb Res 120(5):685-693. https://doi.org/10.1016/j.thromres.2006.12.025

7. Eriksson BI, Borris LC, Dahl OE, Haas S, Huisman MV, Kakkar AK, Muehlhofer E, Dierig C, Misselwitz F, Kalebo P (2006) A once-daily, oral, direct Factor Xa inhibitor, rivaroxaban (BAY 59-7939), for thromboprophylaxis after total hip replacement. Circulation 114(22):2374-2381. https://doi.org/10.1161/circu lationaha.106.642074

8. Turpie AG, Fisher WD, Bauer KA, Kwong LM, Irwin MW, Kalebo P, Misselwitz F, Gent M (2005) BAY 59-7939: an oral, direct factor Xa inhibitor for the prevention of venous thromboembolism in patients after total knee replacement. A phase II doseranging study. J Thromb Haemost 3(11):2479-2486. https://doi. org/10.1111/j.1538-7836.2005.01602.x

9. Eriksson BI, Borris LC, Friedman RJ, Haas S, Huisman MV, Kakkar AK, Bandel TJ, Beckmann H, Muehlhofer E, Misselwitz F, Geerts W, RECORD1 Study Group (2008) Rivaroxaban versus enoxaparin for thromboprophylaxis after hip arthroplasty. N Engl J Med 358(26):2765-2775. https://doi.org/10.1056/NEJMoa0800 374

10. Kakkar AK, Brenner B, Dahl OE, Eriksson BI, Mouret P, Muntz J, Soglian AG, Pap AF, Misselwitz F, Haas S, RECORD2 Investigators (2008) Extended duration rivaroxaban versus short-term enoxaparin for the prevention of venous thromboembolism after total hip arthroplasty: a double-blind, randomised controlled trial. Lancet 372(9632):31-39. https://doi.org/10.1016/S0140 $-6736(08) 60880-6$

11. Kubitza D, Berkowitz SD, Misselwitz F (2016) Evidence-based development and rationale for once-daily rivaroxaban dosing regimens across multiple indications. Clin Appl Thromb Hemost 22(5):412-422. https://doi.org/10.1177/1076029616631427

12. Kwong LM (2011) Therapeutic potential of rivaroxaban in the prevention of venous thromboembolism following hip and knee replacement surgery: a review of clinical trial data. Vasc Health Risk Manag 7:461-466. https://doi.org/10.2147/VHRM.S4441

13. Lassen MR, Ageno W, Borris LC, Lieberman JR, Rosencher N, Bandel TJ, Misselwitz F, Turpie AG, RECORD3 Investigators (2008) Rivaroxaban versus enoxaparin for thromboprophylaxis after total knee arthroplasty. N Engl J Med 358(26):2776-2786. https://doi.org/10.1056/NEJMoa076016

14. Turpie AG, Lassen MR, Davidson BL, Bauer KA, Gent M, Kwong LM, Cushner FD, Lotke PA, Berkowitz SD, Bandel TJ, Benson A, Misselwitz F, Fisher WD, RECORD4 Investigators (2009) Rivaroxaban versus enoxaparin for thromboprophylaxis after total knee arthroplasty (RECORD4): a randomised trial. Lancet 373(9676):1673-1680. https://doi.org/10.1016/S0140 -6736(09)60734-0

15. Mueck W, Borris LC, Dahl OE, Haas S, Huisman MV, Kakkar AK, Kalebo P, Muelhofer E, Misselwitz F, Eriksson BI (2008) Population pharmacokinetics and pharmacodynamics of once- and twice-daily rivaroxaban for the prevention of venous thromboembolism in patients undergoing total hip replacement. Thromb Haemost 100(3):453-461

16. Mueck W, Eriksson BI, Bauer KA, Borris L, Dahl OE, Fisher WD, Gent M, Haas S, Huisman MV, Kakkar AK, Kalebo P, Kwong LM, Misselwitz F, Turpie AG (2008) Population pharmacokinetics and pharmacodynamics of rivaroxaban-an oral, direct factor Xa inhibitor-in patients undergoing major orthopaedic surgery. Clin Pharmacokinet 47(3):203-216. https://doi. org/10.2165/00003088-200847030-00006

17. Ansell J, Hirsh J, Hylek E, Jacobson A, Crowther M, Palareti G (2008) Pharmacology and management of the vitamin K antagonists: American College of Chest Physicians EvidenceBased Clinical Practice Guidelines (8th Edition). Chest $133(6$ Suppl):160S-198S. https://doi.org/10.1378/chest.08-0670 
18. Lee AYY, Levine MN (2003) Venous thromboembolism and cancer: risks and outcomes. Circulation 107(23 suppl 1):I-17-I-21. https://doi.org/10.1161/01.cir.0000078466.72504.ac

19. Agnelli G (2004) Prevention of venous thromboembolism in surgical patients. Circulation 110(24 Suppl 1):IV4-IV12. https://doi. org/10.1161/01.CIR.0000150639.98514.6c

20. Prandoni P, Lensing AW, Piccioli A, Bernardi E, Simioni P, Girolami B, Marchiori A, Sabbion P, Prins MH, Noventa F, Girolami A (2002) Recurrent venous thromboembolism and bleeding complications during anticoagulant treatment in patients with cancer and venous thrombosis. Blood 100(10):3484-3488. https://doi.org/10.1182/blood-2002-01-0108

21. Ay C, Kamphuisen PW, Agnelli G (2017) Antithrombotic therapy for prophylaxis and treatment of venous thromboembolism in patients with cancer: review of the literature on current practice and emerging options. ESMO Open 2(2):e000188. https://doi. org/10.1136/esmoopen-2017-000188

22. Chan N, Sager PT, Lawrence J, Ortel T, Reilly P, Berkowitz S, Kubitza D, Eikelboom J, Florian J, Stockbridge N, Rose M, Temple R, Seltzer JH (2018) Is there a role for pharmacokinetic/ pharmacodynamic-guided dosing for novel oral anticoagulants? Am Heart J 199:59-67. https://doi.org/10.1016/j.ahj.2017.10.002

23. Willmann S, Zhang L, Frede M, Kubitza D, Mueck W, Schmidt S, Solms A, Yan X, Garmann D (2018) Integrated population pharmacokinetic analysis of rivaroxaban across multiple patient populations. CPT Pharmacometr Syst Pharmacol 7(5):309-320. https://doi.org/10.1002/psp4.12288

24. Solms A, Frede M, Berkowitz SD, Hermanowski-Vosatka A, Kubitza D, Mueck W, Spiro TE, Willmann S, Yan X, Zhang L, Garmann D (2019) Enhancing the quality of rivaroxaban exposure estimates using prothrombin time in the absence of pharmacokinetic sampling. CPT Pharmacometr Syst Pharmacol 8(11):805814. https://doi.org/10.1002/psp4.12444

25. Di Nisio M, Ageno W, Rutjes AW, Pap AF, Buller HR (2016) Risk of major bleeding in patients with venous thromboembolism treated with rivaroxaban or with heparin and vitamin $\mathrm{K}$ antagonists. Thromb Haemost 115(2):424-432. https://doi.org/10.1160/ th15-06-0474

26. Lamberts M, Lip GY, Hansen ML, Lindhardsen J, Olesen JB, Raunso J, Olsen AM, Andersen PK, Gerds TA, Fosbol EL, Torp-Pedersen C, Gislason GH (2014) Relation of nonsteroidal anti-inflammatory drugs to serious bleeding and thromboembolism risk in patients with atrial fibrillation receiving antithrombotic therapy: a nationwide cohort study. Ann Intern Med 161(10):690-698. https://doi.org/10.7326/m13-1581

27. Davidson BL, Verheijen S, Lensing AW, Gebel M, Brighton TA, Lyons RM, Rehm J, Prins MH (2014) Bleeding risk of patients with acute venous thromboembolism taking nonsteroidal antiinflammatory drugs or aspirin. JAMA Intern Med 174(6):947953. https://doi.org/10.1001/jamainternmed.2014.946

28. Bauersachs RM, Lensing AW, Prins MH, Kubitza D, Pap AF, Decousus H, Beyer-Westendorf J, Prandoni P (2014) Rivaroxaban versus enoxaparin/vitamin $\mathrm{K}$ antagonist therapy in patients with venous thromboembolism and renal impairment. Thromb J 12:25. https://doi.org/10.1186/1477-9560-12-25

29. Nieto JA, Solano R, Ruiz-Ribo MD, Ruiz-Gimenez N, Prandoni P, Kearon C, Monreal M (2010) Fatal bleeding in patients receiving anticoagulant therapy for venous thromboembolism: findings from the RIETE registry. J Thromb Haemost 8(6):1216-1222. https:// doi.org/10.1111/j.1538-7836.2010.03852.x

30. King G, Zeng L (2001) Logistic regression in rare events data. Political Analysis 9(2):137-163. https://doi.org/10.1093/oxfor djournals.pan.a004868

31. Fisher WD, Eriksson BI, Bauer KA, Borris L, Dahl OE, Gent M, Haas S, Homering M, Huisman MV, Kakkar AK, Kalebo P, Kwong LM, Misselwitz F, Turpie AG (2007) Rivaroxaban for thromboprophylaxis after orthopaedic surgery: pooled analysis of two studies. Thromb Haemost 97(6):931-937

32. Leil TA, Frost C, Wang X, Pfister M, LaCreta F (2014) Modelbased exposure-response analysis of apixaban to quantify bleeding risk in special populations of subjects undergoing orthopedic surgery. CPT Pharmacometrics Syst Pharmacol 3:e136. https:// doi.org/10.1038/psp.2014.34

33. European Medicines Agency Assessment Report for the PostAuthorisation Measure LEG 036.4 Xarelto. Available upon request from: https://www.ema.europa.eu.

Publisher's Note Springer Nature remains neutral with regard to jurisdictional claims in published maps and institutional affiliations. 